\title{
Uniformity and Sensitivity Improvements in Comprehensive Two-Dimensional Gas Chromatography using Flame Ionization Detection with Post-Column Reaction
}

Jim Luong ${ }^{1,2^{*}}$, Yujuan Hua ${ }^{1}$, Ronda Gras ${ }^{1,2}$, Robert A. Shellie ${ }^{3}$

${ }^{1}$ Dow Chemical Canada ULC, Highway 15, Fort Saskatchewan, Alberta, T8L 2P4, Canada, ${ }^{2}$ Australian Centre for Research on Separation Science (ACROSS), University of Tasmania, Private Bag 75 Hobart 7001 Australia,

${ }^{3}$ Centre for Advanced Sensory Science (CASS), School of Exercise and Nutrition Sciences, Deakin University, Burwood Highway, Burwood, Australia

\section{Supporting information:}

Figure S1: Schematic diagram of the second generation two-stage microreactor.

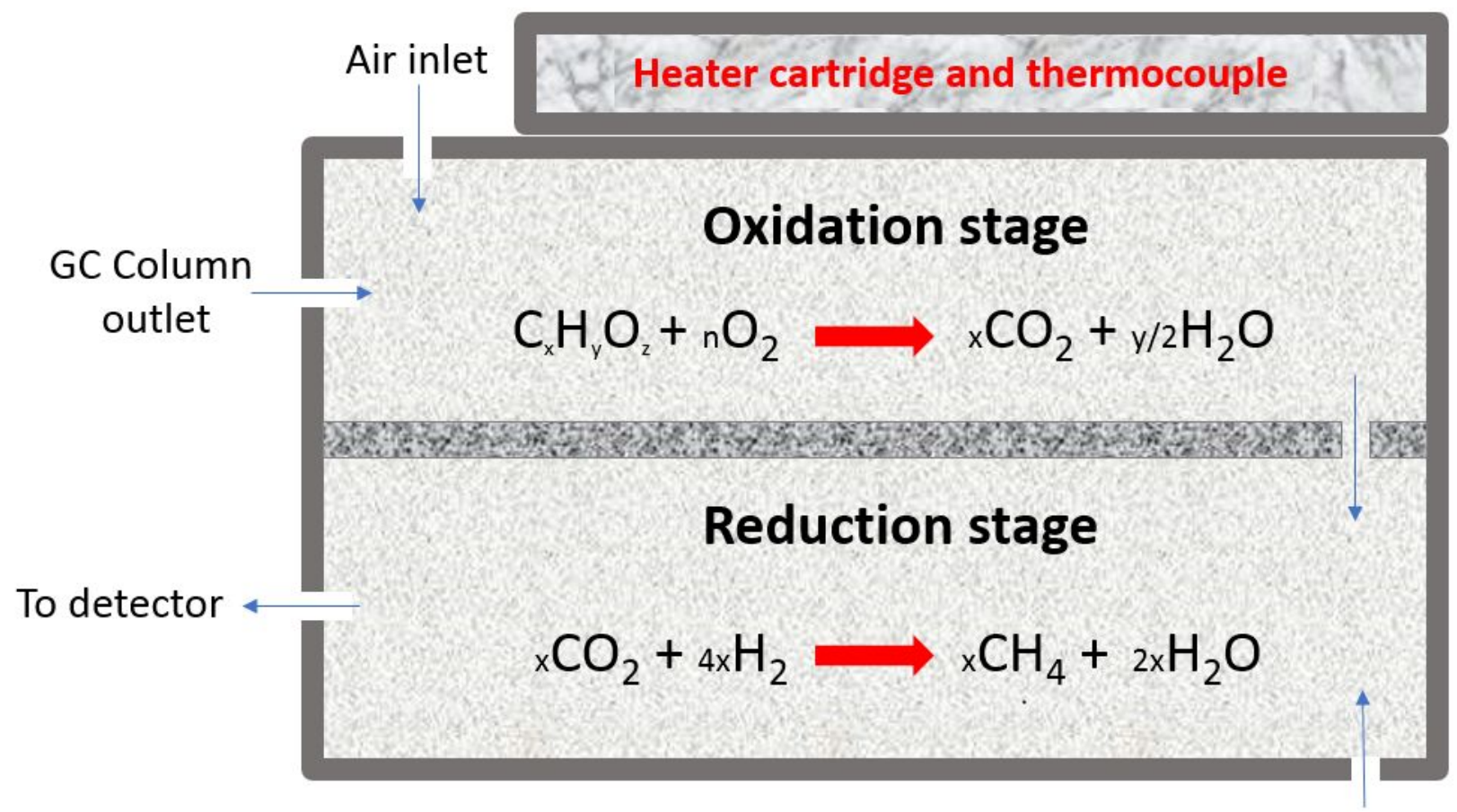

Hydrogen inlet 